\title{
Investigation of Vibrations Energy Harvesting from Passive Car Suspension Using Quarter Car Model Under Bump Excitation
}

\author{
Ayoub Benhiba1*, Abdelmajid Bybi2, Rajae Alla1, Drissi Hilal1, El Ayachi Chater1
}

1Mohammed V University in Rabat, Higher School of Technology in Sale, LASTIMI, Salé, Morocco

2Mohammed V University in Rabat, Higher School of Technology in Sale, MEAT, Salé, Morocco

\begin{abstract}
This paper aims to evaluate the voltage and the electrical power harvested from the car suspension system under bump excitation using a piezoelectric stack. For this purpose, a quarter car system equipped with a piezoelectric stack installed parallel to the suspension's damper is modelled and investigated in temporal domain using MATLAB/Simulink. The studied system is excited, considering different bump amplitudes to evaluate the harvested voltage and power at different speeds. The effect of the suspension's damping coefficient on the harvested voltage and power is also studied and quantified.
\end{abstract}

\section{Introduction}

Renewable energy comes from natural resources that can be replenished in less than one person's lifetime without consuming the earth's resources. Different types of renewable energy can replace traditional fossil fuels harmful to the environment and public health $[1,2]$.

Today, the world continues to rely heavily on fossil fuels and even subsidises them. Meanwhile, the pollution they produce has reached unprecedented levels, ranging from climate-altering greenhouse gases to health-threatening particulates. Furthermore, clean energy could be achieved when something goes wrong by scavenging the waste energy from the ambient environment and converting it into valuable energy. In the automobile sector, one significant energy loss is the dissipation of vibrations' energy by vehicles suspensions shock absorbers due to road irregularity. Research into energy recovery from vehicle suspensions began more than a decade ago as an auxiliary energy source for active suspension and regeneration devices [3,4].

The main methods of implementing an energy harvesting system are to use the strain energy from various mechanical vibrations to generate electrical energy, such as attaching multiple piezoelectric harvesters [5-8], electromagnetic sensors [9-11], electrostatic transducers [12], linear electromagnetic shock absorbers, MR electromagnetic regenerative dampers, hydraulic, rack-pinion, ball-screw, and cable/pullies [13-16]. However, the piezoelectric sensor is widely used due to its simplicity, wide frequency range, electromechanical coupling, and high power density [17-20]. The energy harvesting system generates electricity due to spring compressions and stresses as the car travels. Each piezoelectric element is coupled to a rectifier for converting the $\mathrm{AC}$ output voltage to $\mathrm{DC}$ voltage.

The harvested voltage is used to power several devices in the vehicle or store it in a battery or a capacitor. The resulting electrical charge is proportional to the level of stress $\sigma$, or strain $\mathrm{S}$ applied to the springs. Thus, the more strain subjected to the harvester will generate more electrical charge.

Several researchers have discussed the possibility of installing piezoelectric harvesters in cars' suspension system. Most studies focused on evaluating the energy dissipated from the car's suspension system, not the energy harvesting [17]. In this context, Wang et al. [21] modelled the energy harvesting system as a quarter car model with a piezoelectric element attached in parallel with the spring of the suspension system. It was found that the system is able to generate a theoretical power of up to $2.84 \mathrm{~W}$ when subjected to $1 \mathrm{~g}$ sine wave acceleration. Smith and Wang [19] conducted a comparative study on a simple passive suspension strut containing one damper and one idler. Natsiavas and Papadimitriou [20] proposed optimizing a nonlinear quarter car model's suspension damping and stiffness parameters under random road excitation.

During daily traffic, automobiles overcome different types of road irregularities. These can be random or built for a specific purpose [22]. It is necessary to study several parameters to predict the vehicle's behavior when it overcomes speed bumps. The main variables to be analyzed are, on the one hand, the dimensions and geometry of the speed bump and, on the other hand, the speed and vehicle suspension properties.

In their study, Namee and Witchayangkoon [23] considered a bump with dimensions of $76-150 \mathrm{~mm}$ in height and 0.3-0.9 $\mathrm{m}$ in length with crossing speeds of 8 $\mathrm{km} / \mathrm{h}$ or less.

Akanmu et al. [24] pointed out that the design and construction of the bump should be the government's responsibility. They suggested redesigning the existing speed bumps with a height of more than $210 \mathrm{~mm}$. They recorded the speed bump in the study area up to $250 \mathrm{~mm}$ in height and 0.3 to $0.9 \mathrm{~m}$ in length. To analyze the impact of road bumps on vehicle components and occupants, Pozuelo et al. [25] used MATLAB software to develop a simulation program considering vehicle dynamics, bump geometry, and vehicle speed. They provided possible information and established a set of

\footnotetext{
* Ayoub_benhiba@um5.ac.ma
} 
guidelines for the proper design and installation of road bumps. In the same context, Hassaan [27] used a quarter car model with the passive suspension to study the car's dynamics when crossing a speed bump. The study's conditions were: crossing speed from 5 to $30 \mathrm{~km} / \mathrm{h}$, bump height from 60 to $120 \mathrm{~mm}$, and bump length from 3 to $9 \mathrm{~m}$. The author established a helpful ride comfort chart, i.e., a simple harmonic bump design to achieve any desired crossing speed between 5 and $30 \mathrm{~km} / \mathrm{h}$.

The novelty of this paper is to harvest energy from cars' suspension systems in the presence of speed bumps with different dimensions. The electrical voltage and power harvested using a piezoelectric stack are evaluated by a theoretical quarter car model implemented in MATLAB/Simulink. This work is organized as follows: the section 1 describes the geometric characteristics of speed bumps in Morocco. Section 2 models the vehicle dynamics considering a quarter car suspension system equipped with a piezoelectric vibration energy harvester submitted to bump excitation displacement. In section 3 , we analyze and discuss the obtained results, i.e., the harvested voltage and power. Conclusions are then presented in section 4 .

\section{MATHEMATICAL MODELS}

\subsection{Speed Bumps}

Speed Bumps are in use to calm traffics through speed reduction. However, going down in Bump length to less than one meter makes the issue quite differently. Their design is theoretically subject to well-defined regulatory standards to protect users. Nevertheless, the reality is marked by the non-compliance of the speed bumps with the standards in force, both technically and conceptually.

This study deals not with ride comfort but with energy recovery issues from a suspension system when crossing a bump. A quarter-car model dynamics is studied during crossing such bumps trying to point out its severe effects if the crossing speed increases more than $5 \mathrm{~km} / \mathrm{h}$ with energy harvesting.

\subsubsection{Bump modeling}

As shown in Fig.1, the entry of the studied car model is a slight speed bump as an obstacle to the uniform movement of the vehicle in order to force the driver to slow down its speed to avoid car damage and accidents. In this case, the bump profile excites the dynamics of the vehicle's components, and the vertical motion $\mathrm{Y}$ of the slower depends on the type of bump, i.e., circular type with a height (a) and a length (L) is taken into account.

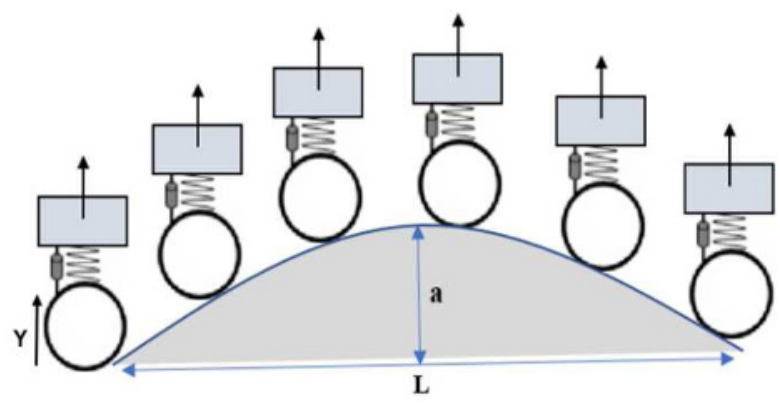

(a)

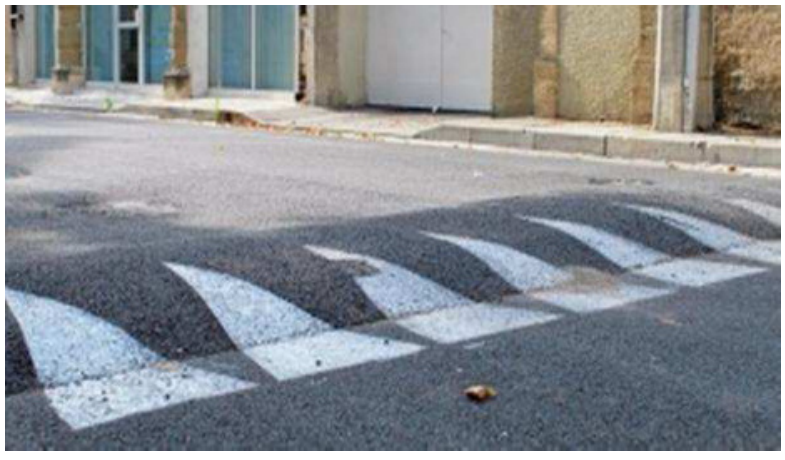

(b)

Fig. 1. Circular Bump: (a) a bump schematic, (b) a natural bump.

The equation of bump in the time domain depends on its length (L), height (a), and car speed (v). It can be defined as follows:

$$
Y=a \sin (\omega \cdot t) \text { for } 0 \leq \mathrm{t} \leq \mathrm{T}
$$

where, $\mathrm{Y}$ is the bump's vertical displacement in time $\mathrm{t}$ from the starting point of the bump, $\Omega$ is the bump's angular frequency assuming it as a harmonic movement (half a cycle), and T denotes the time taken by the car to pass the bump which can be calculated as a follow:

$$
T=\frac{L}{V}
$$

The period $(\tau)$ and the angular frequency $(\omega)$ of the sinusoid wave are given by the following relations:

$\tau=2 T=2 \pi / \omega \quad$ (3) $\quad$ and $\quad \omega=\frac{\pi V}{L}$

The profile's height must be maintained at each point of the section of the roadway, which means that the speed bump must fit the profile across the roadway. In this study, the longitudinal profile of the speed bump is circular and has the following dimensions [36]:

- height: $[0.10 \mathrm{~m}-0.40 \mathrm{~m}]$;

- length: $4 \mathrm{~m} \pm 0.20 \mathrm{~m}$ (construction tolerance);

Equations 1 and 3 are used to draw the bump profile for the circular and simple harmonic bump. The results are given in Fig. 2 for different heights $(100 \mathrm{~mm}, 200 \mathrm{~mm}$, $300 \mathrm{~mm}$, and $400 \mathrm{~mm}$ ) and a length (L) of $4 \mathrm{~m}$. 


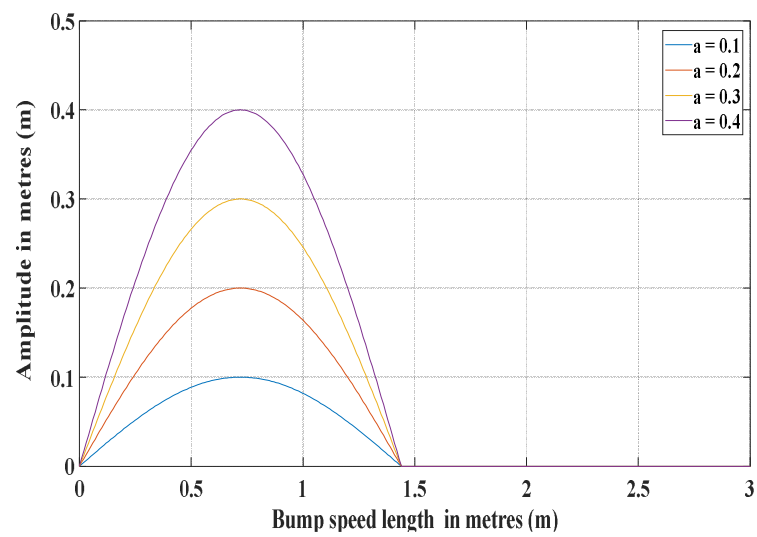

Fig. 2. Road profile of a speed bump for different amplitudes (a) at a speed of $10 \mathrm{~km} / \mathrm{h}$.

\subsection{Quarter car model with piezoelectric vibration energy harvester}

In this section a quarter car suspension model equipped with a piezoelectric stack in parallel with the suspension's spring is developed (Fig. 3).

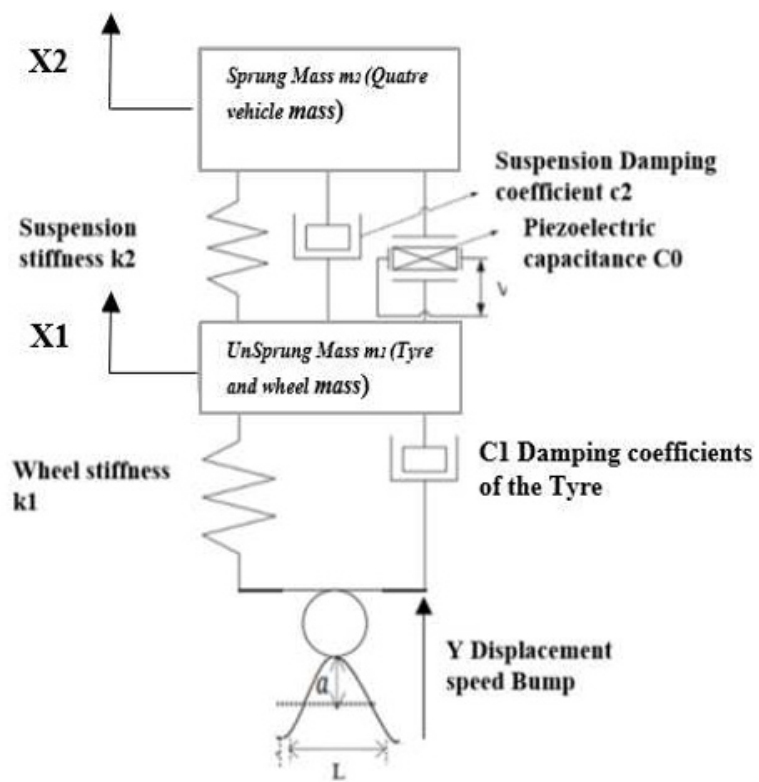

Fig. 3. Quarter car suspension model equipped with a piezoelectric stack [22].

The parameters of the quarter vehicle suspension model are: the bump excitation displacement (y), the unsprung mass or the mass of wheel and tyre of a quarter vehicle $\left(\mathrm{m}_{1}\right)$, the sprung mass or aquarter vehicle's mass $\left(\mathrm{m}_{2}\right)$, the wheel-tyre stiffness $\left(\mathrm{k}_{1}\right)$, the suspension spring stiffness $\left(\mathrm{k}_{2}\right)$, the wheel-tyre damping coefficient $\left(\mathrm{c}_{1}\right)$, the suspension damping coefficient $\left(\mathrm{c}_{2}\right)$, the displacement of the unsprung mass $\left(\mathrm{x}_{1}\right)$; the displacement of the sprung mass $\left(\mathrm{x}_{2}\right)$, and the voltage generated by the piezoelectric material $\mathrm{V}$. The main parameters' values are summarized in table 1.
Table 1. Parameters of the quarter car suspension model with piezoelectric harvester [22]:

\begin{tabular}{|c|c|c|}
\hline Parameters & Description & Value \\
\hline $\mathrm{k}_{1}(\mathrm{kN} / \mathrm{m})$ & Tire stiffness & 135 \\
\hline $\mathrm{c}_{1}(\mathrm{kNs} / \mathrm{m})$ & $\begin{array}{c}\text { Tire damping } \\
\text { coefficient }\end{array}$ & 1.4 \\
\hline $\mathrm{m}_{1}(\mathrm{~kg})$ & $\begin{array}{c}\text { Un-sprung } \\
\text { mass }\end{array}$ & 49.8 \\
\hline $\mathrm{k}_{2}(\mathrm{kN} / \mathrm{m})$ & $\begin{array}{c}\text { Spring } \\
\text { stiffness }\end{array}$ & 5.7 \\
\hline $\mathrm{c}_{2}(\mathrm{kNs} / \mathrm{m})$ & $\begin{array}{c}\text { Damping } \\
\text { coefficient }\end{array}$ & 1 \\
\hline $\mathrm{m}_{2}(\mathrm{~kg})$ & Sprung mass & 466.5 \\
\hline $\mathrm{C}(\mathrm{F})$ & $\begin{array}{l}\text { Piezoelectric } \\
\text { clamped } \\
\text { capacitance }\end{array}$ & $1.89 * 10^{-8}$ \\
\hline $\mathrm{R}(\Omega)$ & $\begin{array}{l}\text { Electrical } \\
\text { resistance }\end{array}$ & 30455.3 \\
\hline$\alpha(\mathrm{N} / \mathrm{V})$ & Force factor & $1.52 * 10^{-3}$ \\
\hline
\end{tabular}

For the piezoelectric element, the relationship between electrical and mechanical variables is derived as follows [29]:

$$
F_{p}=K_{p} Y_{p}(t)+\alpha V_{p}(t)
$$

where, $\mathrm{K}_{\mathrm{p}}$ is the rigidity of the piezoelectric stack, $\mathrm{Y}_{\mathrm{p}}$ is the relative displacement between the sprung and unsprung masses, and $\alpha$ is the force factor. The piezoelectric parameters are defined as follow:

$$
\begin{gathered}
K_{p}=\frac{C_{p}^{E} A_{p}}{l_{p}} \\
\alpha=e^{33} \frac{A_{p}}{l_{p}} \\
C_{p}=\frac{\varepsilon_{33} A_{p}}{l_{p}}
\end{gathered}
$$

where $A_{p}$ and $L$ denote the sections and the thickness of the piezoelectric stack, the total length of the stack is defined by the following relation [29]:

$$
l_{p}=N h_{p}
$$

The electrical relation governing the energy harvesting can be presented by [29]:

$$
\frac{V_{p}}{R}=\alpha \dot{Y}_{p}(t)-C \dot{V}_{p}(t)
$$

where $Y_{p}$ is the relative displacement, $\alpha$ is the force factor, $V_{p}$ is the piezoelectric output voltage, $R$ is the external resistor, and $\mathrm{C}$ is the piezoelectric capacitance. The equations of time motion governing the quarter car model illustrated in Fig. 3 can be surmised as follows: The following relation gives the equation of the vertical motion of the unsprung mass:

$$
\begin{aligned}
m_{1} \ddot{x}_{1}=\alpha V+k_{2}[ & \left.x_{2}(t)-x_{1}(t)\right]+c_{2}\left[\dot{x}_{2}(t)-\dot{x}_{1}(t)\right] \\
& -k_{1}\left[x_{1}(t)-y(t)\right] \\
& -c_{1}\left[\dot{x}_{1}(t)-\dot{y}(t)\right]
\end{aligned}
$$


Applying Laplace transformation, the relations (12), (13) and (14) are easily obtained:

$$
\begin{aligned}
& m_{1} x_{1} s^{2}=\alpha V+k_{2}\left[\begin{array}{l}
\left.x_{2}-x_{1}\right]+c_{2} s\left[x_{2}-x_{1}\right]-k_{1}\left[x_{2}-y\right] \\
-
\end{array} \quad c_{1} s\left[x_{1}-y\right] \quad(12)\right. \\
& \begin{aligned}
x_{1}\left[m_{1} s^{2}+s\left(c_{1}+c_{2}\right)\right. & \left.+\left(k_{1}+k_{2}\right)\right] \\
& =\alpha V+x_{2}\left[k_{2}+c_{2} s\right]+y\left[c_{1} s+k_{1}\right]
\end{aligned} \\
& x_{1}=\frac{\alpha}{\left[m_{1} s^{2}+s\left(c_{1}+c_{2}\right)+\left(k_{1}+k_{2}\right)\right]} V \\
& +\frac{\left[k_{2}+c_{2} s\right]}{\left[m_{1} s^{2}+s\left(c_{1}+c_{2}\right)+\left(k_{1}+k_{2}\right)\right]} x_{2} \\
& +\frac{\left[c_{1} s+k_{1}\right]}{\left[m_{1} s^{2}+s\left(c_{1}+c_{2}\right)+\left(k_{1}+k_{2}\right)\right]} y
\end{aligned}
$$

The vertical displacement of the unsprung mass can be written as:

$$
x_{1}=A_{1} V+A_{2} x_{2}+A_{3} y
$$

Where:

$$
\begin{aligned}
& A_{1}=\frac{\alpha}{\left[m_{1} s^{2}+s\left(c_{1}+c_{2}\right)+\left(k_{1}+k_{2}\right)\right]} \\
& A_{2}=\frac{\left[k_{2}+c_{2} s\right]}{\left[m_{1} s^{2}+s\left(c_{1}+c_{2}\right)+\left(k_{1}+k_{2}\right)\right]} \\
& A_{3}=\frac{\left[c_{1} s+k_{1}\right]}{\left[m_{1} s^{2}+s\left(c_{1}+c_{2}\right)+\left(k_{1}+k_{2}\right)\right]}
\end{aligned}
$$

The equation of vertical motion of the quarter sprung mass is given by the relation:

$$
m_{2} \ddot{x}_{2}(t)=-k_{2}\left[x_{2}(t)-x_{1}(t)\right]-c_{2}\left[\dot{x}_{2}(t)-\dot{x}_{1}(t)\right]-\alpha V
$$

Applying Laplace transformation, the relations (20), (21) and (22) are easily obtained:

$$
\begin{aligned}
& m_{2} x_{2} s^{2}=-k_{2}\left[x_{2}-x_{1}\right]-c_{2} s\left[x_{2}-x_{1}\right]-\alpha V \\
& x_{2}\left[m_{2} s^{2}+c_{2} s+k_{2}\right]=x_{1}\left[k_{2}+c_{2} s\right]-\alpha V \\
& x_{2}=\frac{\left[k_{2}+c_{2} s\right]}{\left[m_{2} s^{2}+c_{2} s+k_{2}\right]} x_{1}-\frac{\alpha}{\left[m_{2} s^{2}+c_{2} s+k_{2}\right]} V
\end{aligned}
$$

The sprung mass's vertical displacement can be written as:

where:

$$
x_{2}=A_{3} x_{1}-A_{4} V
$$

$$
\begin{aligned}
& A_{3}=\frac{\left[k_{2}+c_{2} s\right]}{\left[m_{2} s^{2}+c_{2} s+k_{2}\right]} \\
& A_{4}=\frac{\alpha}{\left[m_{2} s^{2}+c_{2} s+k_{2}\right]}
\end{aligned}
$$

The equations that govern for the equivalent electrical system as derived in equation (10) can be modified and written separately in Laplace transformation as:

The harvested voltage is:

$$
V=\alpha R\left(\dot{x}_{2}(t)-\dot{x}_{1}(t)\right)-C_{0} R \dot{V}
$$

Applying Laplace transformation, the following relations are obtained:

$$
\left(C_{0} R s+1\right) V=\alpha R x_{2} s-\alpha R x_{1} s
$$

$$
\begin{gathered}
V=\frac{\alpha R s}{\left(C_{0} R s+1\right)} x_{2}-\frac{\alpha R s}{\left(C_{0} R s+1\right)} x \\
V=A_{5} \mathrm{x}_{2}-A_{5} \mathrm{x}_{1}
\end{gathered}
$$

The transfer function equations between the oscillator displacement and the excitation displacement (bump speed) are derived from equations. (11), (19), and (29) as follow:

$$
\left\{\begin{array}{l}
\frac{x_{1}}{y}=\frac{A_{6}}{A_{7}} \\
\frac{x_{2}}{y}=\frac{A_{8}}{A_{9}}
\end{array}\right.
$$

Where:

$$
\begin{aligned}
A_{6}= & \left(k_{1}+c_{1} s\right)\left[\left(k_{2}+c_{2} s+m_{2} s^{2}\right)\left(1+R C_{0} s\right)+\alpha^{2} R s\right] \\
A_{7}= & \left(m_{1} s^{2}+c_{1} s+k_{1}\right)\left[\left(m_{2} s^{2}+c_{2} s+k_{2}\right)\left(1+R C_{0} s\right)+\alpha^{2} R s\right] \\
& +\left[\left(k_{2}+c_{2} s\right)\left(1+R C_{0} s\right)+\alpha^{2} R s\right] m_{2} s^{2} \\
A_{8}= & \left(k_{1}+c_{1} s\right)\left[\left(k_{2}+c_{2} s\right)\left(1+R C_{0} s\right)+\alpha^{2} R s\right] \\
A_{9}= & \left(m_{1} s^{2}+c_{1} s+k_{1}\right)\left[\left(m_{2} s^{2}+c_{2} s+k_{2}\right)\left(1+R C_{0} s\right)+\alpha^{2} R s\right] \\
& +\left[\left(k_{2}+c_{2} s\right)\left(1+R C_{0} s\right)+\alpha^{2} R s\right] m_{2} s^{2}
\end{aligned}
$$

Therefore, the transfer function equation between the output voltage and excitation displacement bump speed is given by the relations (35) and (36):

$$
\begin{aligned}
& \frac{V}{y}=\frac{V}{x_{2}-x_{1}} \frac{x_{2}-x_{1}}{y} \\
& \frac{V}{y}=\frac{A_{10}}{A_{11}}
\end{aligned}
$$

Where:

$$
\begin{aligned}
& A_{10}=-m_{2} s^{3}\left(k_{1}+c_{1} s\right) \alpha R \\
& \begin{aligned}
A_{11}=\left(m_{1} s^{2}+c_{1} s+\right. & \left.k_{1}\right)\left[\left(m_{2} s^{2}+c_{2} s+k_{2}\right)\left(1+R C_{0} s\right)+\alpha^{2} R s\right] \\
& +\left[\left(k_{2}+c_{2} s\right)\left(1+R C_{0} s\right)\right. \\
& \left.+\alpha^{2} R s\right] m_{2} s^{2}
\end{aligned}
\end{aligned}
$$

As a result, the output voltage subjected to a bump excitation is given by:

$$
V=\frac{A_{12}}{A_{13}} y
$$

Where:

$A_{12}=-m_{2} s^{3}\left(k_{1}+c_{1} s\right) \alpha R$

$A_{13}=\left(m_{1} s^{2}+c_{1} s+k_{1}\right)\left[\left(m_{2} s^{2}+c_{2} s+k_{2}\right)\left(1+R C_{0} s\right)+\alpha^{2} R s\right]$

$$
+\left[\left(k_{2}+c_{2} s\right)\left(1+R C_{0} s\right)+\alpha^{2} R s\right] m_{2} s^{2}(41)
$$

Finally, the electrical power can be obtained using the relation:

$$
P=\frac{V^{2}}{R}
$$

In order to verify the output voltage and power calculated using the above temporal response analysis, Matlab Simulink is applied to conduct a time-domain simulation. The simulation scheme utilized to investigate the performance of the harvesting system is shown in Fig. 4.

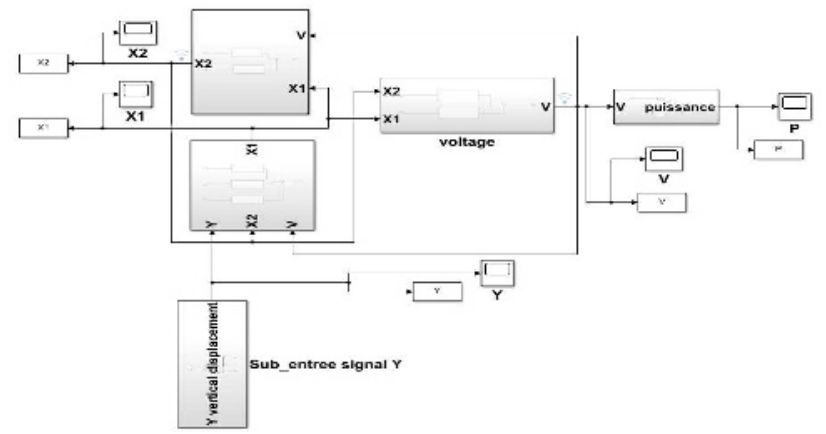

Fig. 4. Utilized Simulink scheme to evaluate the output voltage and harvested power. 
The quarter-car model is two degrees of freedom (2DOF) system, which means that it has two natural frequencies that may be determined from the displacement amplitude values of each subsystem with the displacement amplitude of the input road (speed bump). The equation (30) is utilized to determine the system's resonance frequencies. As expected, two resonance frequencies are obtained $0.51 \mathrm{~Hz}$ and $6.83 \mathrm{~Hz}$ (Fig. 5).

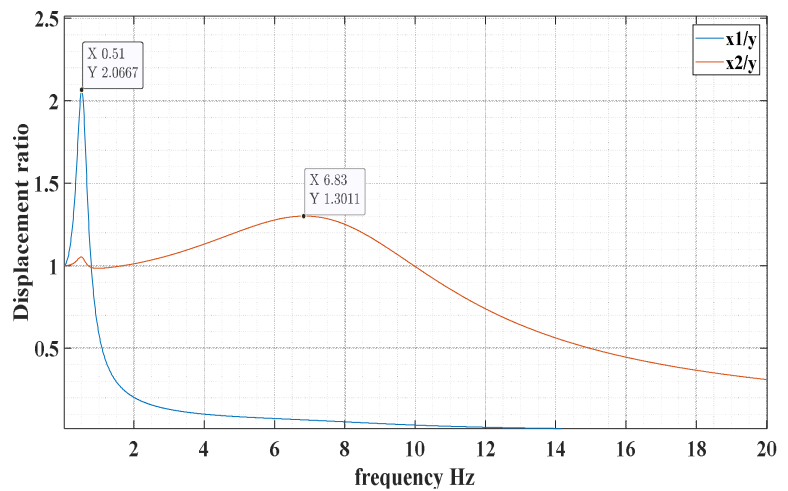

Fig. 5. Displacement amplitude ratios are relative to $m_{1}$ and $\mathrm{m}_{2}$ with respect to the input displacement amplitude.

To evaluate the effect of the load resistance on the harvested voltage, it is assumed that the electrical resistance changes from 0 to $10^{7} \Omega$ and the other parameters are constants. The output voltage calculated by the analysis method is shown in Fig 6. After analysis it is found that the optimal electrical resistance's value is about $6^{*} 10^{7} \mathrm{ohm}$.

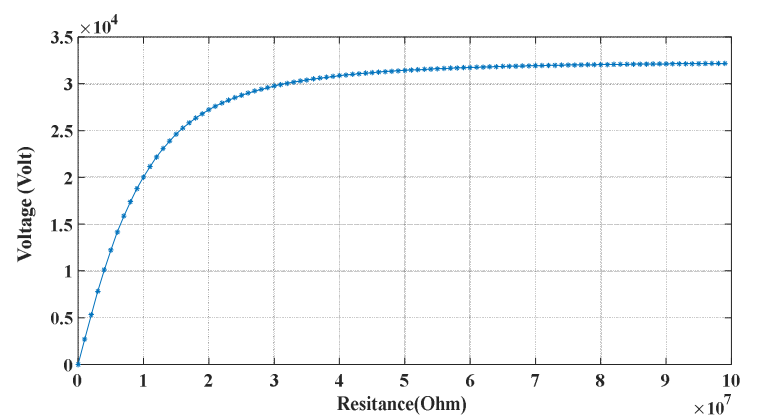

Fig. 6: Variation of the output voltage with the electric load resistance.

\section{RESULTS AND DISCUSSION}

In order to verify the performance of the harvesting system in the time-domain, the output voltage and power are computed using Matlab Simulink. In the simulation scheme, input data is represented by a sinusoidal cycle function with a first half-sine cycle of $100 \mathrm{~mm}$ to $400 \mathrm{~mm}$ amplitude and $4 \mathrm{~m}$ width (Fig.4). The harvested power is calculated considering the voltage square divided by the load resistance. The predicted output voltage and harvested power in the time-domain are displayed using Matlab scop modules. Simulation results are shown in figures 7 to 12 .

\subsection{Harvested voltage and power for different suspension damping coefficients and car speeds}

The effects of the suspension damping $c_{2}$ and vehicle speed on the harvested electrical voltage and power are first investigated. The harvested electrical voltage and power obtained from the quarter car suspension model as generated by MATLAB Simulink are shown in figures 7, 8, and 9, for different damping coefficients 1 , 5,10 , and $15 \mathrm{kNs} / \mathrm{m}$ and for different bump passing speeds 10,20 and $30 \mathrm{~km} / \mathrm{h}$. The other suspension system parameters are considered constants.

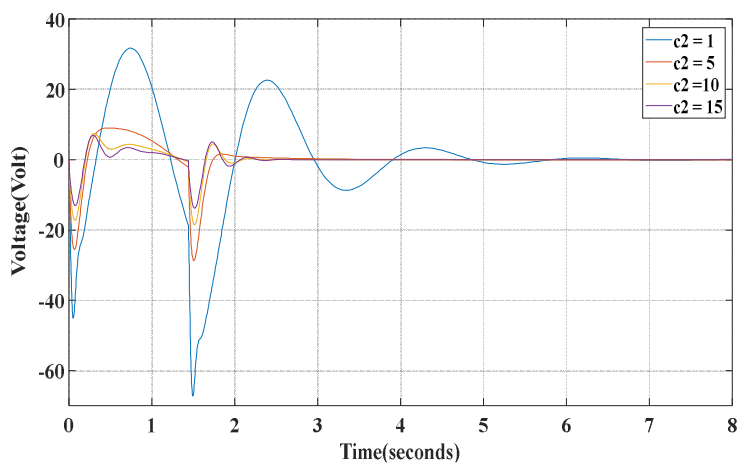

(a)

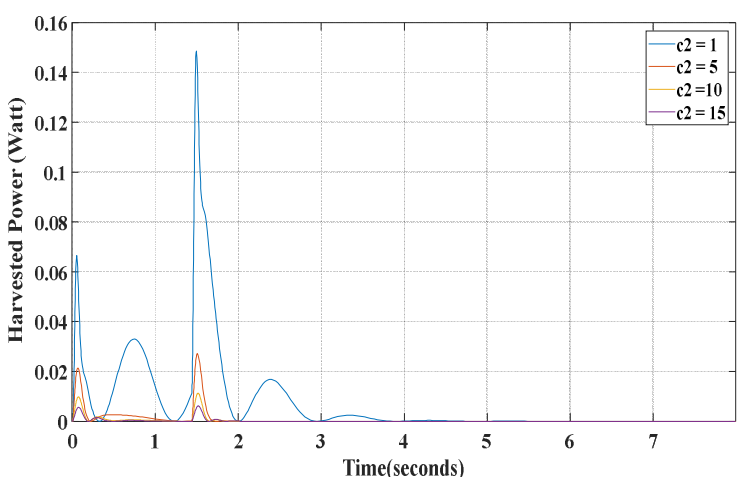

(b)

Fig. 7. Harvested voltage and power for different damping coefficients at a speed of $10 \mathrm{~km} / \mathrm{h}$ : (a) electrical voltage and (b) electrical power.

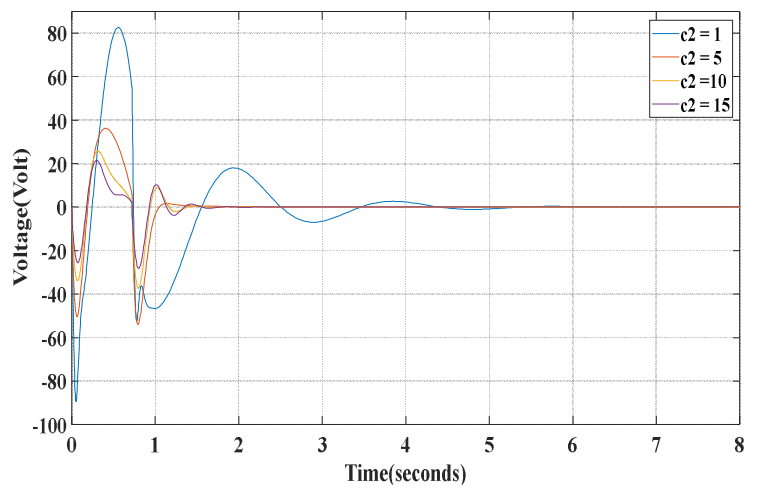

(a) 


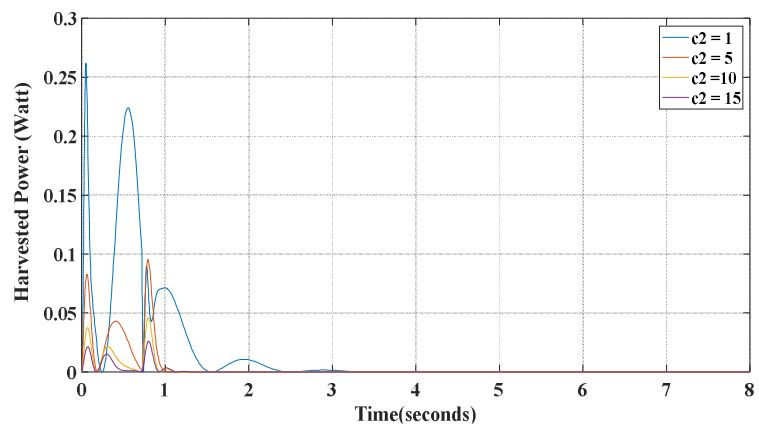

(b)

Fig. 8. Harvested voltage and power for different damping coefficients at a speed of $20 \mathrm{~km} / \mathrm{h}$ : (a) electrical voltage and (b) electrical power.

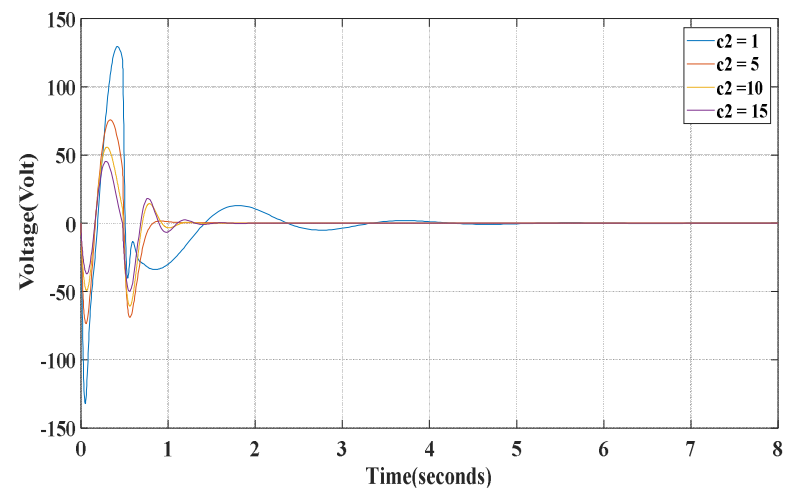

(a)

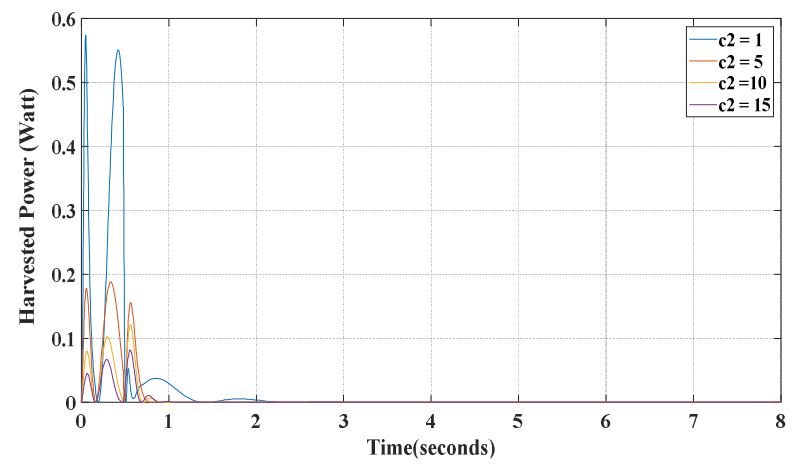

(b)

Fig. 9. Harvested voltage and power for different damping coefficients at a speed of $30 \mathrm{~km} / \mathrm{h}$ : (a) electrical voltage and (b) electrical power.

It can be observed from the simulation results that for a given car speed value, e.g. $10 \mathrm{~km} / \mathrm{h}$ increasing the suspension damping coefficient from 1 to $15 \mathrm{kNs} / \mathrm{m}$ decrease the obtained electrical voltage and power. It can be also seen that the voltage and power values increase with the augmentation of car speed for all suspension damping coefficient. The simulated maximum output voltage and power values are 129.52 $\mathrm{V}$ and $0.574 \mathrm{~W}$ respectively. These values are obtained for suspension damping of $1 \mathrm{kNs} / \mathrm{m}$ and car speed value of $30 \mathrm{~km} / \mathrm{h}$.

\subsection{Harvested voltage and power for different bump speed amplitudes}

The effect of bump speed amplitude (a) on the harvested electrical voltage and power is also studied in this section. The harvested electrical voltage and power obtained from the quarter car suspension model are shown in figures 10,11 , and 12 for different bump amplitudes of $0.1,0.2,0.3$, and 0.4 and at different car speeds of 10,20 , and $30 \mathrm{~km} / \mathrm{h}$. The other suspension system parameters are considered constants.

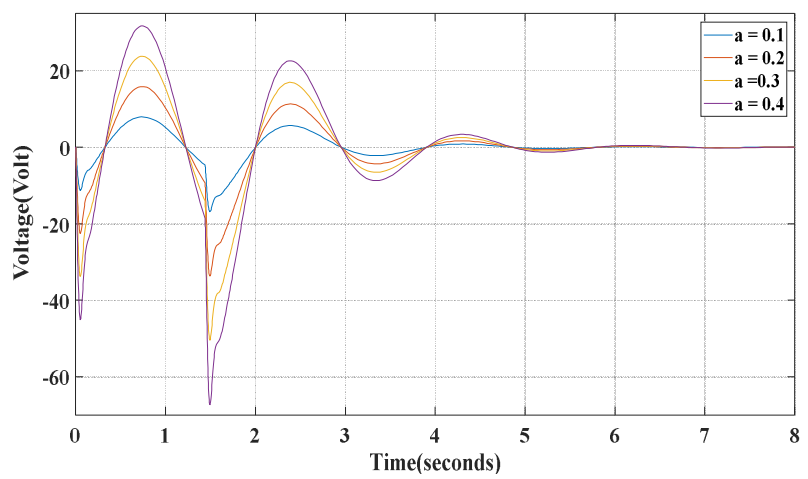

(a)

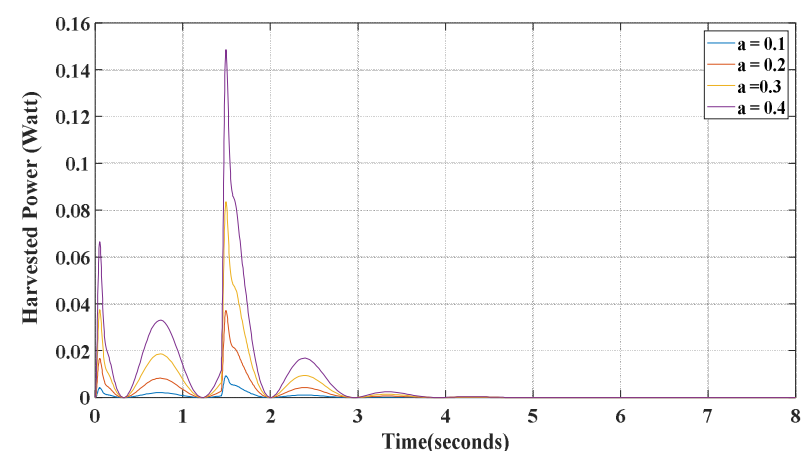

(b)

Fig. 10. Harvested voltage and power for different bump amplitudes at a speed of $10 \mathrm{~km} / \mathrm{h}$ : (a) electrical voltage and (b) electrical power.

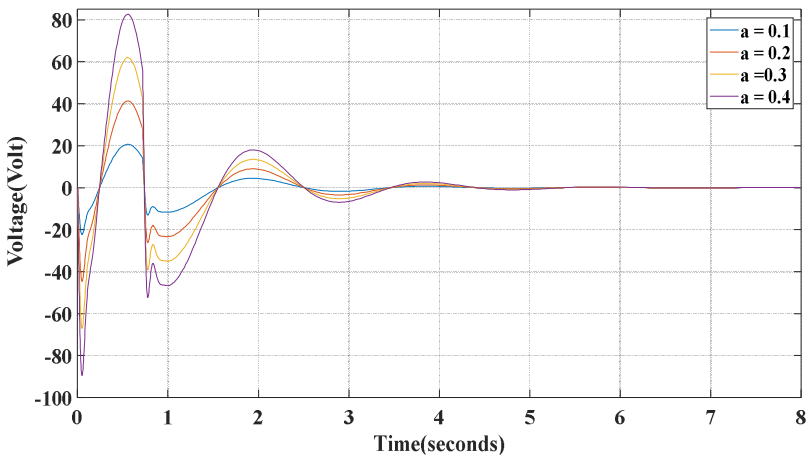

(a)

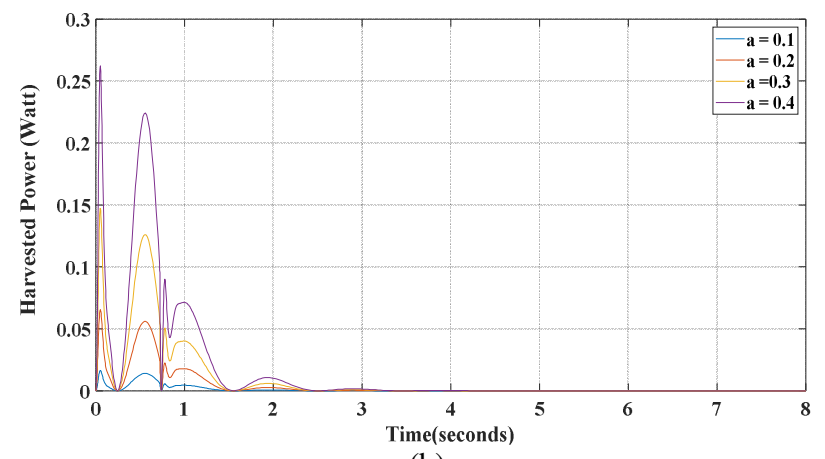

(b)

Fig. 11. Harvested voltage and power for different bump amplitudes at a speed of $20 \mathrm{~km} / \mathrm{h}$ : (a) electrical voltage and (b) electrical power. 


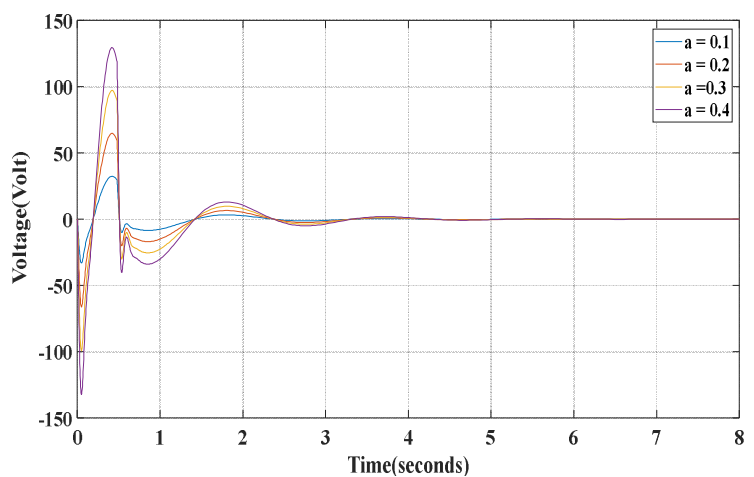

(a)

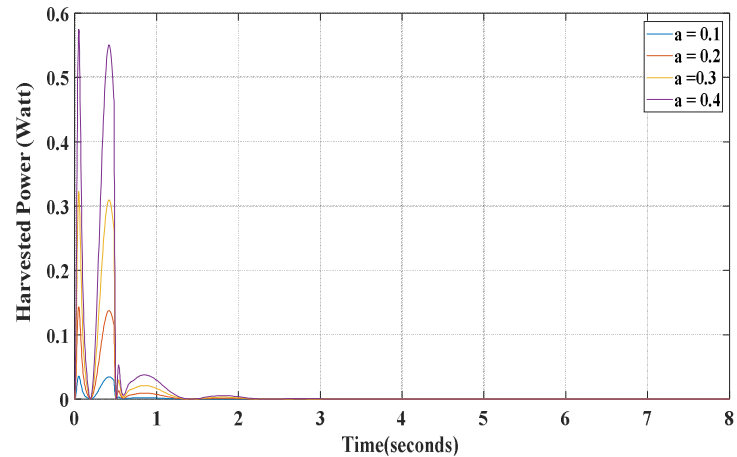

(b)

Fig. 12. Harvested voltage and power for different bump amplitudes at a speed of $30 \mathrm{~km} / \mathrm{h}$ : (a) electrical voltage and (b) electrical power.

According to the obtained results, it is clear that increasing bump amplitude (a) improves the quantity of harvested electrical voltage and power. The simulated results also indicate that the maximum voltage and power are registered at a speed of $30 \mathrm{~km} / \mathrm{h}$ for a damping coefficient of $1 \mathrm{kNs} / \mathrm{m}$ and bump speed amplitude of 0.4 . For this amplitude, the maximum harvested electrical voltage and power increase with car speed, e.g. at 30 $\mathrm{km} / \mathrm{h}$, the obtained voltage and power are $129.52 \mathrm{~V}$ and $0.574 \mathrm{~W}$ respectively. Finally, it can be concluded from the results that the energy harvesting depends on the car speed, the damping coefficient, and also the bump speed amplitude.

In comparison with the literature, D. Al-Yafeai et al. found that the electrical voltage and power collected on a $C$ class road using quarter car model can be increased from $1.46 \mathrm{~V}$ to $2.3 \mathrm{~V}$ and from $0.21 \mathrm{~mW}$ to $0.53 \mathrm{~mW}$ respectively, when the speed is increased from $40 \mathrm{~km} / \mathrm{h}$ to $100 \mathrm{~km} / \mathrm{h}$ [30] Moreover, Xiao et al. proposed a dimensionless method to predict the harvested electrical voltage and power for a $2 \mathrm{DOF}$ vibration energy harvesting system [22]. In this study a quarter car suspension model equipped with a piezoelectric material was investigated considering a sine wave acceleration excitation of $1 \mathrm{~g}$ amplitude. The predicted voltage and power RMS values were $194.14 \mathrm{~V}$ and $1.23 \mathrm{~W}$ respectively.

In comparison with the previous works, we obtained a maximum voltage and power of $129.52 \mathrm{~V}$ and $0.574 \mathrm{~W}$ respectively, when passing a circular Bump with height of 0.4 at a car speed of $30 \mathrm{~km} / \mathrm{h}$.

\section{Conclusion}

This paper investigates and quantifies the electrical voltage and power harvested from a car suspension system using a piezoelectric stack. The quarter car model is implemented in Matlab Simulink to examine the system's behavior in the time-domain and evaluate the harvested electrical voltage and power when passing a circular bump speed. To study the effect the suspension's damping coefficient on energy harvesting, its value is varied from 1 to $15 \mathrm{kNs} / \mathrm{m}$. Also, the car is excited under input bump with different heights (100 $\mathrm{mm}$ to $400 \mathrm{~mm}$ ) to observe its effect on the harvested voltage and power. It is found that the maximum voltage and power (129.52 $\mathrm{V}$ and $0.574 \mathrm{~W})$ are obtained when passing a circular bump having a height $\mathrm{a}=0.4$ at a speed of $30 \mathrm{~km} / \mathrm{h}$. The effect of the other suspension parameters and other bump geometries on energy harvesting will also be investigated in future works.

\section{References}

1. Mark Z. Jacobson, Mark A. Delucchi, Zack A.F. Bauer, Savannag C. Goodman, William E. Chapman, Mary A. Cameron, Cedric Bozonnat. Goldstrom, Eleanor M. Hennessy. 100\% clean and renewable wind, water, and sunlight all-sector energy roadmaps for 139 countries of the world. Joule 1, P 108-121 (2017).

2. Heard, B.P, Brook, B.W Wigley, T.M Bradshaw, C.J. Burden of proof A comprehensive review of the feasibility of $100 \%$ renewable electricity systems. Renew Sustain. Energy Rev. 76, P 11221133 (2017).

3. Y. Suda and T. Shiba, "New Hybrid Suspension System with Active Control and Energy Reg System Dynamic Supplement, Vol. 25,

4. Y. Suda, S. Nakadai and K. Nakano, "Hybrid Suspension System with Skyhook Control and Energy Regeneration (Development of Self Powered Active Suspension)," Vehicle System Dynamic Supplement, Vol. 19, 1998, pp. 619634.

5. K. E. Graves, P. G. Iovenitti, D. Toncich, "Electromagnetic regenerative damping in vehicle suspension systems," International Journal of Vehicle Design, vol. 24, no. 2-3, pp. 182-197, (2000).

6. L. Segel and X. Lu, "Vehicular resistance to motion as influenced by road roughness and highway alignment," Australian Road Research, vol. 12, no. 4, pp. 211-222, (1982).

7. X. Wang, Frequency analysis of vibration energy harvesting systems. Academic Press, (2016)

8. D. Al-Yafeai, T. Darabseh, A-H. I. Mourad, "Quarter vs. Half Car Model Energy Harvesting Systems," in 2019 IEEE Advances in Science and Engineering Technology International Conferences (ASET), pp. 1-5, (2019). 
9. B. Lafarge, C. Delebarre, S. Grondel, O. Curea, and A. Hacala, "Analysis and optimization of a piezoelectric harvester on a car damper," Physics Procedia vol. 70, pp. 970-973 (2015).

10. S. F. Ali and S. Adhikari, "Energy harvesting dynamic vibration absorbers," Journal of Applied Mechanics, vol. 80, no. 4, pp. 1-9 (2013).

11. C. Madhav and S. F. Ali, "Harvesting energy from vibration absorber under random excitations," IFAC-Pap., vol. 49, no. 1, pp. 807-812 (2016).

12. Z. Fang, X. Guo, L. Xu, H. Zhang, “An optimal algorithm for energy recovery of hydraulic electromagnetic energy-regenerative shock absorber," Applied Mathematics \& Information Sciences, vol. 7, no. 6, pp. 2207-2214 (2013).

13. S. Gopalakannan, S. P. Kumar, V. Premsagar, T. R. Pradeep, "Design, Fabrication and Testing of Regenerative Shock Absorber (Linear Alternator Type)," International Journal of Applied Engineering Research, vol. 10, no. 8, pp. 61336137 (2015).

14. B. Scully, L. Zuo, J. Shestani, and Y. Zhou, "Design and characterization of an electromagnetic energy harvester for vehicle suspensions," in ASME 2009 International Mechanical Engineering Congress and Exposition, pp. 1007-1016 (2009).

15. Y. B. Kim, W. G. Hwang, C. D. Kee, H. B. Yi, "Active vibration control of a suspension system using an electromagnetic damper," Proceedings of the Institution of Mechanical Engineers, Part J Automobile Engineering, vol. 215, no. 8, pp. 865873 (2001).

16. P. Mitcheson and E. Yeatman, "Energy harvesting for pervasive computing," Perada Magazines, pp. 1-3, 2008. De preference citer un autre papier

17. P. Múčka, "Energy-harvesting potential of automobile suspension," Vehicle System Dynamics, vol. 54, no. 12, pp. 1651-1670 (2016).

18. M. A. Abdelkareem, Xu Lin., Ali, Mohamed Kamal Ahmed, Elagouz, Ahmed, Mi, Jia Guo, Sijing, Liu, Yilun, Zuo, Lei "Vibration energy harvesting in automotive suspension system: A detailed review," Appl. Energy, vol. 229, pp. 672 699, (2018).

19. Z. Jin-qiu, P. Zhi-zhao, Z. Lei, Z. Yu, “A review on energy-regenerative suspension systems for vehicles," in Proceedings of the world congress on engineering, vol. 3, pp. 3-5 (2013).

20. N. H. Amer, R. Ramli, H. M. Isa, W. N. L. Mahadi, M. A. Z. Abidin, "A review of energy regeneration capabilities in controllable suspension for passengers' car," Energy Education Science and Technology: Energy Science and Research., vol. 30, no. 1, pp. 143-158, (2012).

21. M. Smith and F. Wang, "Performance benefits in passive vehicle suspensions employing inerters", Vehicle System Dynamics, vol.42, no.4, pp.235257, (2004).
22. H. Xiao, X. Wang, et S. John, “ A dimensionless analysis of a $2 \mathrm{DOF}$ piezoelectric vibration energy harvester ", Mechanical Systems and Signal Processing, vol. 58-59, p 6-21 (2015)

23. A. M. Molan et A. A. Kordani, "Optimization of Speed Hump Profiles Based on Vehicle Dynamic Performance Modeling ", J. Transp. Eng., vol. 140, no 8, p.10-18 (2014)

24. S. Namee and B. Witchayangkoon, Crossroads vertical speed control devices: suggestion from observation,International Journal of Engineering, Management and Applied Sciences and Technologies, P 161-171 (2011),

25. A. Akanmu, F. Alabi and O. Agboola, Towards efficient application of speed bumps as traffic calming device in Saki West Local Government area of Oyo state, Nigeria, J. of Environmental Sciences and Resources Management,pp 127-136 (2014).

26. D. Pozuelo, A. Gauchia, E. Olmeda and V. Draz, Bump modeling and vehicle vertical dynamics prediction,Hindawi Publishing Corporation, Advances in Mechanical Engineering, Vol.2014, p 10-12, (2014).

27. G. A. Hassaan, Car dynamics using quarter model and passive suspensions: Part II: A novel simple harmonic hump, Journal of Mechanical and Civil Engineering, 12 (1), 93-100 (2015).

28. Norme de ralentisseur routière de type dos d'âne ou de type trapézoïdal Caracteristiques geometriques https://www.imanor.gov.ma/Norme/nm-13-1-2042.

29. E. Lefeuvre, A. Badel, C. Richard, L. Petit, and D. Guyomar, "A comparison between several vibration-powered piezoelectric generators for standalone systems,"Sensors and Actuators A: Physical., vol. 126, no. 2, pp. 405-416, (2006).

30. D. Al-Yafeai, T. Darabseh, et A.-H. I. Mourad, «Energy Harvesting from Car Suspension System Subjected to Random Excitation », (2020). 